\title{
Biyofilm oluşumu ve kontrollü antibiyotik salımı
}

\section{Biofilm production and controlled release of antibiotics}

\author{
Berna Kankılıç ${ }^{1}$, Feza Korkusuz ${ }^{2}$ \\ ${ }^{1}$ Türk Standardları Enstitüsü, Ankara \\ ${ }^{2}$ Hacettepe Üniversitesi Tıp Fakültesi, Spor Hekimliği Anabilim Dalı, Sıhhiye, Ankara
}

\begin{abstract}
İmplant ilişkili enfeksiyonlar hastanın yaşam kalitesini olumsuz yönde etkileyen, tedavi masrafları oldukça yüksek olan tablolardır. Çoğunlukla cerrahi prosedürler sırasında meydana gelen kontaminasyon ile gelişen enfeksiyon sonrasında geleneksel tedavi yöntemi, implantın eksplante edilmesi sonrasında enfeksiyon bölgesine debridman uygulaması ve hastaya yaklaşık 4-6 hafta boyunca intravenöz olarak uygulanan antibiyotik tedavisidir. Enfeksiyona neden olan patojen türleri oldukça çeşitli olup, bunların birçoğu kendilerini dış ortamlardan koruyarak çoğalmalarını ve yayılmalarını sağlayan ve üç boyutlu bir yapı olan biyofilm oluşturma kabiliyetine sahiptir. Biyofilm oluşumu enfeksiyon tedavisini oldukça güçleştirdiği için erken dönemde biyofilmin oluşmasını engellemek tedavinin ana noktalarından biridir. Ancak enfeksiyon bölgesinde kan dolaşımının azalması ve biyofilmle mücadele için oldukça yüksek dozlarda antibiyotiğe gerek duyulması nedeniyle kontrollü antibiyotik salım sistemleri gün geçtikçe daha önemli hale gelmektedir. Bu sistemler taşıdıkları antibiyotiği doğrudan enfeksiyon bölgesine taşıdıkları için toksik reaksiyonlara neden olmamakta ve enfeksiyon daha kolay şekilde kontrol altına alınabilmektedir. Kontrollü antibiyotik salım sistemleri farklı biyomalzemelerin tek başına veya çoklu kullanımı ile oluşturulabilmekte olup, tek başına implant olarak ya da metal implantların yüzeyine kaplanarak kullanılabilmektedir.
\end{abstract}

Anahtar sözcükler: implant ilişkili enfeksiyon; biyofilm; antibiyotik; kontrollü salım
Implant-related infections are those that negatively affect the quality of life of the patient and have high treatment costs. After the infection, which mostly occurs during the surgical procedures, with the contamination, the traditional treatment method is debridement to the infection site after the implant is explanted and the antibiotic treatment administered intravenously to the patient for about 4-6 weeks. The types of pathogens that cause infection are quite diverse, many of which have the ability to create biofilm, a three-dimensional structure that protects themselves from external environments and allows them to multiply and spread. Since biofilm formation makes infection treatment very difficult, it is one of the main points of treatment to prevent the formation of biofilm in the early period. However, due to the decreased blood circulation in the infection area and the need for high doses of antibiotics to combat biofilm controlled antibiotic release systems are becoming more and more important day by day. Since these systems carry the antibiotic directly to the infection site, they do not cause any toxic reactions and the infection can be controlled more easily. Controlled antibiotic release systems can be manufactured alone or with multiple uses of different biomaterials, and can be used as implants alone or by coating on the surface of metal implants.

Key words: implant-related infection; biofilm; antibiotic; controlled release
G ünümüzde biyomedikal teknolojilerin gelişmesi ve ortalama insan ömrünün artması nedeniyle implant kullanımı giderek artmaktadır. İmplant kullanımı her ne kadar hasta yaşam kalitesini yükseltse de, implant ilişkili enfeksiyon riski olası ve yaygındır. ${ }^{[1]}$ İmplant üretiminde biyouyumluluğu kanıtlanmış biyomalzemeler kullanılmasına rağmen, cerrahi yolla invaziv olarak yerleştirilen bu tıbbi cihazlar konakta immun yanıt oluşturmaktadır. İmplant ilişkili enfeksiyonlar; bu immun yanıt, patojen ve biyomalzemeyi de içeren karmaşık etkileşimler nedeniyle ortaya çıkmaktadır. ${ }^{[2]}$ İmplant ilişkili enfeksiyonlar çoğunlukla cerrahi sırasında mikrobiyal kontaminasyon yoluyla meydana gelmektedir ve bu patojenlerden bazıları biyofilm oluşturma özelliğine sahiptir. İmplant ilişkili enfeksiyonlarda biyofilm oluşturma becerisine sahip en sık rastlanan patojenler Staphylococcus aureus (S.aureus), Staphylococcus epidermidis (S.epidermidis) ve Pseudomonas aeruginosa (P.aeruginosa)'dır. ${ }^{[3,4]}$ Biyofilm, bu patojenlerin bir yüzeye, ki implant ilişkili enfeksiyonlarda bu yüzey implantın kendisidir, geri dönüşümsüz tutulumu ile oluşan üç boyutlu ekstrasellüler polimerik bir

- Illetişim adresi: Berna Kankılıç, Erler Mah. Türk Kızılayı Cad. Deniz Lojmanları F Blok No:14 Etimesgut, Ankara

Tel: 0535 - 8462398 e-posta: uysalberna@yahoo.com

- Geliș tarihi: 22 Mayıs $2020 \quad$ Kabul tarihi: 8 Haziran 2020 


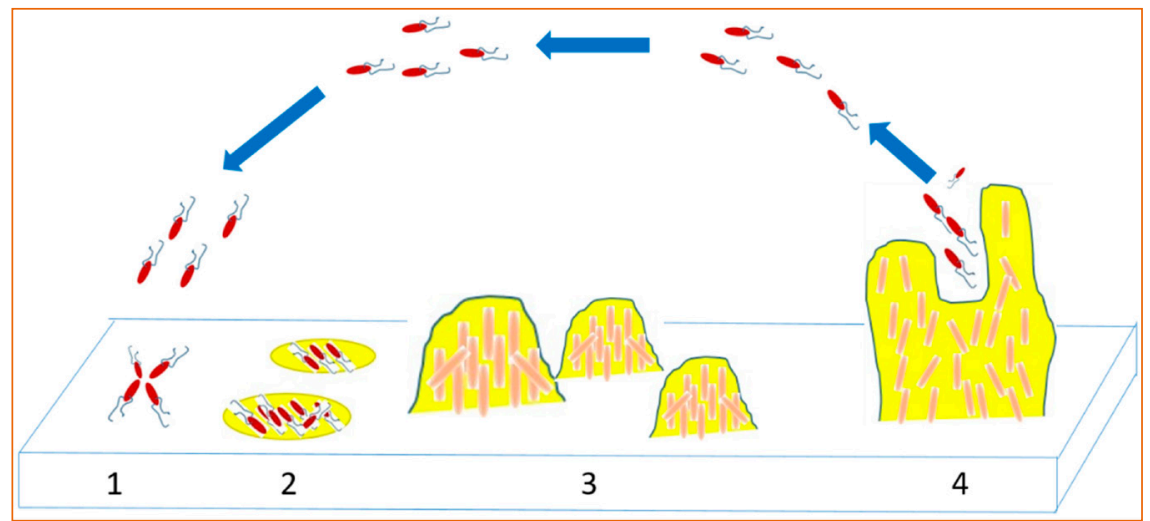

Şekil 1. Biyofilm oluşumu aşamaları:

1. Yüzeye yapışma aşaması.

2. Mikro koloni oluşumu ve ekstrasellüler polimerik madde üretimi aşaması.

3. Olgunlaşma ve üç boyutlu yapı oluşturma aşaması.

4. Kopma ve ayrılma aşaması.

matristir. ${ }^{[5]}$ Gross ve ark. patojende bulunan teikoik asitlerin biyofilm oluşumunun önde gelen nedeni olduğunu belirtmiştir. ${ }^{[6]}$ Ayrıca, polisakkarit hücreler arası adhezinin (PIA) de biyofilm oluşumunda rol oynadığını gösteren çalışmalar mevcuttur. ${ }^{[7]}$ Biyofilm oluşumu dört aşamadan meydana gelmektedir. ilk aşama olan tutunmada patojen van der Waal's kurveti veya elektrostatik etkileşimler yardımı ile yüzeye bağlanır. Bir sonraki aşama olan mikro koloni oluşturmada yüzeye yapışan ve stabil hale gelen patojen bölünerek çoğalmaya başlar ve ekstrasellüler polimerik madde üretimi gerçekleşir. Giderek çoğalan patojenler mikro koloniler oluşturur ve bir sonraki aşama olan olgunlaşma evresine geçilir. ${ }^{[5]}$ Bu aşamada biyofilm ortamında bakteriler, eşik hücre yoğunluğuna ulaşırlar ve quorum veya çoğunluk algılaması olarak bilinen kemotaksi ile iletişim kurabilirler. ${ }^{[8]}$ Biyofilmin üç boyutlu yapısı yine bu aşamada oluşmaktadır. Son aşama olan kopma ve ayrılmada ise, olgun patojen durağan formdan hareketli forma geçer, biyofilmden ayrılarak enfekte olmamış bölgelere göç eder ve yeni biyofilmler oluşturur (Şekil 1). ${ }^{[2]}$ Biyofilm patojenleri antibiyotik ajanlar, fagositoz, oksijen radikali ve proteaz savunmaları gibi dış çevre koşullarından korur. Bir diffüzyon bariyeri olarak hareket ederek antimikrobiyal ajanların geçirgenliğini azalttı̆̆ından, biyofilm içindeki patojenleri yok etmek için daha yüksek antimikrobiyal ajan konsantrasyonlarına ihtiyaç vardır. ${ }^{[9]}$

Biyofilmler, doku kültürü plakası, tüp yöntemi, Kongo Kırmızısı Agar yöntemi, biyolüminesan analizi ve floresan mikroskopi gibi çeşitli tekniklerle saptanabilir. En sık kullanılan biyofilm tespit yöntemi olan doku kültürü plakası yönteminde biyofilm oluşturan bakteriler, $1 \%$ glikoz içeren triptikaz soya besi yerine inokule edilir. Bakteri kültürü, kuyucuk başına $200 \mu \mathrm{l}$ olacak şekilde 96 kuyucuklu doku kültürü plakasına yerleştirilir. Plaka $37^{\circ} \mathrm{C}$ 'de $24-48$ saat inkübe edilir.
Daha sonra planktonik bakteriler dökülür ve kuyular yıkanır. Kuyucuklar \%0,1 kristal viyole boya ile doldurulur ve daha sonra fazla lekeden kurtulmak için su ile yıkanır. Kalan kristal viyole boya \%95 etanol ile çözündürülür ve optik yoğunluk (OD) 620 nm'de ELISA okuyucuda ölçülür (Şekil 2). ${ }^{[10]}$

Başka bir teknik olan tüp yönteminde, bakteriler \%1 glikoz içeren triptikaz soya besi yerine inokule edilir, ancak bu sefer test tüpleri bir doku kültür plakası yerine kullanılır. Doku kültürü yönteminde olduğu gibi aynı prosedürler uygulanır, ancak bu sefer biyofilm oluşumu kontrol suşlarına göre kalitatif olarak tespit edilir. Biyofilm oluşumu zayıf/hiç, orta veya güçlü olarak skorlanır. Kongo Kırmızısı Agar yönteminde, Kongo Kırmızısı indikatörü sakkaroz içeren beyin kalp infüzyon agar içine eklenir. Mikroorganizmalar Kongo Kırmızı Agar plakalarına inoküle edilir ve $37^{\circ} \mathrm{C}$ 'de 24 saat inkübe edilir.

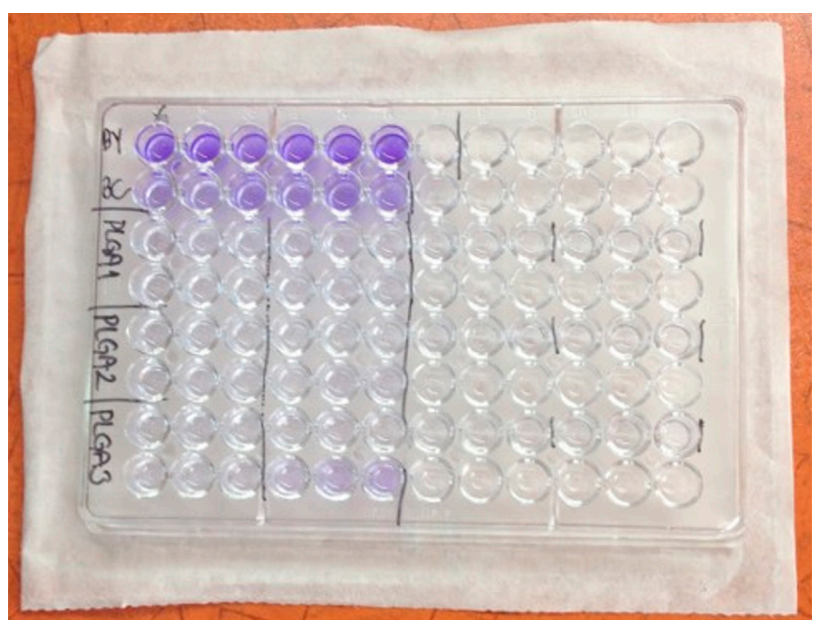

Şekil 2. Kristal viyole yöntemi ile biyofilm oluşumu tespiti. Koyu mor renkli kuyucuklar biyofilm oluşturan mikroorganizma varlığını göstermektedir. 
Siyah koloniler içeren kuru kristaller kalitatif biyofilm oluşumu sağlamaktadır. ${ }^{[11]}$ Xiong ve ark. biyolüminesan bakterilerle fare enfeksiyonu modelinde biyofilm oluşumunu izlemiştir. ${ }^{[12]}$ Lux operon sokulan S.aureus ve P.aeruginosa, bir görüntüleme sistemi yardımılla gerçek zamanlı olarak izlenir. Ayrıca floresan bakterilerde biyofilm oluşumunun tespiti için çok fotonlu lazer tarama mikroskopisi de kullanılmaktadır. ${ }^{[13]}$

Biyofilm oluşumunun da gerçekleşmiş olduğu enfeksiyonun sistemik veya parenteral ilaç iletimi ile ortadan kaldırılamadığı durumlarda kontrollü ilaç salım sistemleri dikkat çekmektedir. Enfeksiyon nedeniyle enfekte olan bölgede kan dolaşımı bozulduğundan, sistemik olarak verilen ilaçlar çoğu zaman enfeksiyon alanına ulaşamamaktadır. Kontrollü ilaç salım sistemleri içerdikleri ilacı doğrudan enfeksiyon alanına iletirken, ilacın etkinliğini artırmak ve toksik etkilerini azaltmak gibi avantajlara da sahiptir. Kontrollü ilaç salımında, ilaç konsantrasyonu istenen etki süresi için terapötik seviyededir. ${ }^{[14]}$

Kontrollü ilaç salım sistemlerinde ilaç için bir taşıyıcı bulunmalı ve ilaç diffüzyon, kimyasal reaksiyon veya çözücü aktivasyonu ile serbest bırakılmalıdır. Diffüzyon sistemlerinde, bir matris (monolitik sistemler) veya bir rezervuar (membran sistemleri) vardır ve ilaçlar bu sistemler yoluyla yayılır. Bir matriste; ilaç eşit olarak çözülür veya dağıtılıır ${ }^{[15]}$, rezervuar sistemlerinde ilaçlar taşıyıcı ${ }^{[16]}$ ile çevrelenir.

Kimyasal olarak kontrol edilen ilaç salım sistemlerinde, ilaç taşıyıcı materyalin su veya kimyasal reaksiyonla bozulmasıyla salınır. Ayrıca ilaç, su veya kimyasal reaksiyonla bozunabilen ve ilacı serbest bırakabilen kararsız bağlarla taşıyıcı materyale de bağlanabilir. Çözücü ile aktive edilen mekanizmada ise, taşıyıcı materyalin şişmesi veya harici suyun sisteme girip verdiği ozmotik etki ile ilaç serbest bırakılmaktadır. İlaç salım sistemleri biyobozunmaz ve biyobozunur sistemler olarak sınıflandırılabilir ve üretimlerinde metal, polimer, seramik veya farklı malzeme gruplarının birleştirilerek oluşturduğu kompozitler gibi birçok farklı taşıyıcı madde kullanılabilir.

Ortopedi alanında biyofilm oluşturabilen bakterilerden kaynaklı implant ilişkili enfeksiyonların tedavisinde kontrollü ilaç salım sistemleri ile gerçekleştirilen birçok farklı çalışma bulunmaktadır.

Kankilic ve ark. tarafından yapılan çalışmada, vankomisin içeren poli-l-laktik asit (PLLA)/ $\beta$-TCP kompozitleri, metisiline dirençli S.aureus'u (MRSA) in vitro olarak kontrol etmek üzere geliştirilmiştir. Vankomisin içermeyen kompozitler negatif kontrol olarak kullanılmış ve başka bir gruptaki kompozitler vankomisin salımını uzatmak için PLLA solüsyonuna daldırılarak kaplanmıştır. Kaplanmış kompozitler altı hafta boyunca in vitro ortamda vankomisin salgılamıştır. Sıçan modelinde implant ile ilişkili osteomiyeliti (IRO) kontrol etmek için de aynı vankomisin içeren kompozitler kullanılmıştır. IRO modeli, titanyum partikülleri ile tibial defekt içine metisilin dirençli S.aureus (MRSA) inokülasyonu ile oluşturulmuştur. Enfeksiyon modeli üç hafta sonra radyografik analiz ile doğrulanmıştır. Sahte (sham) operasyon da yapılmış ve kontrol grubu olarak kullanılmıştır. Kompozitlerin implantasyonundan sonra, radyolojik ve histolojik skorlar 1 . ve 6 . haftalarda mikrobiyolojik bulgularla birlikte ölçülmüştür. IRO vankomisin içeren kompozitlerde ortadan kalkmış ve MRSA sadece vankomisin içermeyen kompozitlerden izole edilmiştir. ${ }^{[17]}$

Aragon ve ark. kemik enfeksiyonu tedavisinde kullanılmak üzere elektrosprey metoduyla rifampisin içeren poli(laktid-ko-glikolid) (PLGA) partikülleri üretmiş ve sonra bu partikülleri elektrospining yöntemi ile üretilmiş polikaprolakton nanofiberler üzerine tutturmuşlar ve emilebilir iskeleler elde etmişlerdir. Gerçekleştirilen ilaç salım çalışmalarına göre rifampisin ilk altı saat içerisinde başlangıç patlaması ile birlikte ortama yüksek oranda salınmış olup, 28 gün boyunca iskeleden ilaç salımı devam etmiş ve ilacın \%82'si salınmıştır. Gerçekleştirilen mikrobiyolojik çalışmalara göre salınan ilaç miktarının S.aureus ve Escherichia coli (E.coli)'nin elimine edilmesi için yeterli olduğu bulunmuş olup, ilaç salımı gerçekleştiren bu iskele sistemi ile kemik enfeksiyonlarının önüne geçilebileceği belirtilmiştir. ${ }^{[18]}$

Balato ve ark. kolistin ve linezolid dahil olmak üzere farklı antibiyotikler içeren kemik çimento disklerinin yüzeyindeki biyofilm büyümesini kantitatif olarak değerlendirmiştir. Vankomisin içeren kemik çimentosu, bakteriyel inokülasyondan 96 saat sonra MRSA biyofilm oluşumunu azaltmada etkili bulunmamıştır. Buna karşı linezolid, klindamisin ve aminoglikozit yüklü çimento hala etkili olarak bulunmuştur. 72 ve 96 saatlik gözlemlerde S.epidermidis biyofilm sadece tobramisin ve gentamisin disklerinde mevcuttur. 48 saatlik gözlemden başlayarak tüm zaman aralıklarında kolistin yüklü çimento disklerinde P.aeruginosa biyofilmleri bulunurken, tobramisin veya gentamisin disklerinde bu biyofilm hiç saptanmamıştır. Çalışma sonuçlarına göre farklı türde bakteriler için farklı türde ilaç kullanımının önemli olduğu ve tedavi öncesi patojen kaynağının bulunup tedavinin bu şekilde planlamasının önemli olduğu belirtilmektedir. ${ }^{[19]}$

Barros ve ark. gerçekleştirdikleri çalışmada aktif farmasötik içerik kullanmak yerine salım sisteminde bakteriyofajları kullanmayı tercih etmişlerdir. Bakteriyofajlar mevcut antimikrobiyal kemoterapi tedavilerine göre belirli bakteri suşlarını enfekte etme ve öldürme kapasitesine sahiptir. Çalışmada 
bakteriyofaj yüklü aljinat nanohidroksiapatit hidrojeller üretilmiş ve enfeksiyon kontrolü ve doku rejenerasyonu açısından incelenmiştir. Bakteriyofaj yüklü hidrojeller osteoblast hücre proliferasyonunu inhibe etmezken, ex vivo embriyonik civciv femoral segmental defekt modeline yapılan implantasyonda osteojenik yanıt görülmüştür. Mikrobiyolojik çalışmalara göre tasarlanan taşıyıcı sistem çoklu ilaç direnci bulunan Enterococcus faecalis (E.faecalis)'in yapışmasını ve kolonizasyonunu önlemektedir. ${ }^{[20]}$

Horprasertkij ve ark. ortopedik enfeksiyonlarının yönetimi için kullanılan yöntemlerden biri olan implant yüzeyinin kaplanması için vankomisin yüklü poli(laktid-ko-glikolid) nanoküreler ve gentamisin yüklü poli(laktid-ko-glikolid) nanoküreleri sprey kaplama yöntemi ile Schanz çivilerinin (pinlerinin) yüzeyine yerleştirmişlerdir. Kaplamada bulunan vankomisin ve gentamisin ilk günde görülen patlama etkisi ile birlikte 70 gün boyunca salınmış ve kümülatif olarak bu süre içerisinde nanokürelere yüklenen vankomisinin \%97.57'si ve gentamisinin \%80.59'unun in vitro ortamda salındığı tespit edilmiştir. In vitro antimikrobiyal testler S.aureus ve E.coli ile gerçekleştirilmiştir. Yazarlar enfeksiyonun önlenmesi için ilk altı saat içinde bakteri adhezyonunun engellenmesinin enfeksiyonun önlenmesinde önemli rol oynadığını belirtmişlerdir. Elde edilen verilere göre antibiyotik yüklü nanoküreler bir haftaya kadar S.aureus ve E.coli üremesini engellemiş ve sağladıkları uzun süreli salım süresine göre implant ilişkili kemik enfeksiyonlarının önlenmesinde iyi bir strateji olabilecekleri belirtilmiştir. [21]

İmplant ilişkili enfeksiyonların önlenmesinde kullanılan diğer kontrollü antibiyotik salım sistemleri çalışmaları Tablo 1'de özetlenmiştir.

Tablo 1. Kontrollü antibiyotik salım sistem çalışmaları

\begin{tabular}{|c|c|c|c|}
\hline Kaynak & Macha ve ark. ${ }^{[22]}$ & Qiao ve ark. ${ }^{[23]}$ & Pawar ve ark. ${ }^{[24]}$ \\
\hline Malzeme & $\begin{array}{l}\text { Vankomisin yüklü hidroksiapatit } \\
\text { içeren poli laktik asit (PLA) film } \\
\text { kompoziti. }\end{array}$ & $\begin{array}{l}\text { Moksifloksasin içeren PLGA mikro- } \\
\text { küre (MOX-PLGA) ve moksifloksa- } \\
\text { sin/rifampisin içeren PLGA mikrokü- } \\
\text { re (MOX/RIF-PLGA). }\end{array}$ & Vankomisin, siprofloksasin ve sefuroksim içeren kitosan süngerler. \\
\hline Amaç & $\begin{array}{l}\text { Dental, ortopedik ve nöral protez- } \\
\text { lerde ilaç salımı gerçekleştiren kap- } \\
\text { lama geliştirmek. }\end{array}$ & $\begin{array}{l}\text { Ortopedik enfeksiyonların tedavisin- } \\
\text { de moksifloksasin/rifampisin içeren } \\
\text { PLGA mikrokürenin etkinliğinin de- } \\
\text { gerlendirilmesi }\end{array}$ & $\begin{array}{l}\text { Ortopedik implant ilişkili enfeksiyonlarda farklı antibiyotik türleri } \\
\text { içeren kitosan süngerlerin ilaç salım sistemi olarak kullanılmasının } \\
\text { araştııılması. }\end{array}$ \\
\hline Metod & $\begin{array}{l}\text { Deniz mercanı hidrotermal metod } \\
\text { yardımıyla hidroksiapatite dönüştü- } \\
\text { rülmüştür. Nano ve mezo gözenek- } \\
\text { lere sahip hidroksiapatite vakum } \\
\text { yardımı ile gentamisin yüklemesi } \\
\text { gerçekleştirilmiş ve kloroformda çö- } \\
\text { zülen PLA ile karşstırılmıştır. Farkı } \\
\text { bir deney grubu için PLA yalnızca } \\
\text { gentamisin ile karışıtırılmıştır. Elde } \\
\text { edilen kompozitler daldırma yönte- } \\
\text { mi ile Ti6Al4V disklere ve vida şek- } \\
\text { lindeki dental implant yüzeyine kap- } \\
\text { lanmıştır. S.aureus ve P.aeruginosa } \\
\text { suşları ile kompozit yüzeylerinde } \\
\text { statik biyofilm oluşumu değerlen- } \\
\text { dirilmiştir. }\end{array}$ & $\begin{array}{l}\text { Her iki deney grubundaki mikrokü- } \\
\text { reler çift emülsiyon çözücü buhar- } \\
\text { laştırma metodu ile üretilmiştir. Bir } \\
\text { hafta boyunca } 10 \mathrm{mg} \text { mikroküreden } \\
\text { salınan ilaç miktarları yüksek perfor- } \\
\text { manslı sıvı kromatografisi (HPLC) } \\
\text { ile ölçülmüşstür. Kirby-Bauer meto- } \\
\text { duyla mikrokürelerin antimikrobiyal } \\
\text { etkinlikleri iki farklı S.aureus suşunda } \\
\text { (211447779 ve } 21872738 \text { ) deģerlen- } \\
\text { dirilmiştir. Mikrokürelerden salınan } \\
\text { antibiyotik miktarlarının biyofilm } \\
\text { oluşturma inhibisyonları kalitatif } \\
\text { ve kantitatif olarak kristal viyole ve } \\
\text { konfokal lazzer tarama mikroskopisi } \\
\text { (CLSM) ile test edilmiştir. }\end{array}$ & $\begin{array}{l}\text { Farklı antibiyotikler içeren kitosan süngerler dondurarak kurtuma } \\
\text { yöntemiyle elde edilmiştir. Süngerlerden salınan antibiyotik mik- } \\
\text { tarları tespit edilmiş ve in vitro antibakteriyel etkileri Kirby-Bauer } \\
\text { yöntemi ile değerlendirilmiştir. In vivo çalışma için altı haftalık erkek } \\
\text { Spraque-Dawley sıçanlarında sırtlarında oluşturulan cep inzisyonia- } \\
\text { rına kitosan süngerler yerleştirilmiş ve } 42 \text { gün boyunca süngerlerden } \\
\text { salınan antibiyotik miktarları HPLC ile tespit edilmiştir. }\end{array}$ \\
\hline Sonuçlar & $\begin{array}{l}\text { Her iki deney grubunda } 15 \text { hafta } \\
\text { boyunca gentamisin salınımı ger- } \\
\text { çekleşirken, hidroksiapatit içeren } \\
\text { kompozitlerde salım miktarlan } \\
\text { diffüzyon zorluğu nedeniyle daha } \\
\text { az miktardadır. Buna rağmen her } \\
\text { iki grupta biyofilm yoğunluğu ista- } \\
\text { tistiksel olarak anlamlı şekilde dü- } \\
\text { şüktür ve bu kompozitlerin implant } \\
\text { ilişskili enfeksiyonların önlenmesinde } \\
\text { umut vaat edici olabileceği belirtil- } \\
\text { miştir. }\end{array}$ & $\begin{array}{l}\text { İlaç salım sonularına göre } 24 \text { saat } \\
\text { içerisinde antibiyotiklerin hiç biri } \\
\text { patlama etkisi göstermemiştir. Bir } \\
\text { hafta sonunda MOX-PLGA'dan } \\
\text { moksifloksasinin \%81,2'si salınırken, } \\
\text { MOX/RIF-PLGA'dan salınan anti- } \\
\text { biyotik miktarı moksifloksasin için } \\
\% 67,9 \text { iken rifampisin için \%54,4'tür. } \\
\text { S.aureus } 211447779 \text { için MOX/RIF- } \\
\text { PLGA MOX-PLGA'ya göre istatistik- } \\
\text { sel olarak anlamlı daha geniş inhi- } \\
\text { bisyon zonu oluştururken, S.aureus } \\
21872738 \text { MOX-PLGA'ya karşı di- } \\
\text { renç gösterirken, MOX/RIF-PLGA } \\
\text { mikroküreleri inhibisyon etkisi göster- } \\
\text { mektedir. Kristal viyole ve CLSM test- } \\
\text { lerine göre her iki mikroküre öncül } \\
\text { ve olgun biyofilmlere karşı etkiliyken } \\
\text { MOX/RIF-PLGA mikrokürelerin biyo- } \\
\text { film inhibisyonuna etkisi daha yüksek } \\
\text { olarak bulunmuştur. }\end{array}$ & 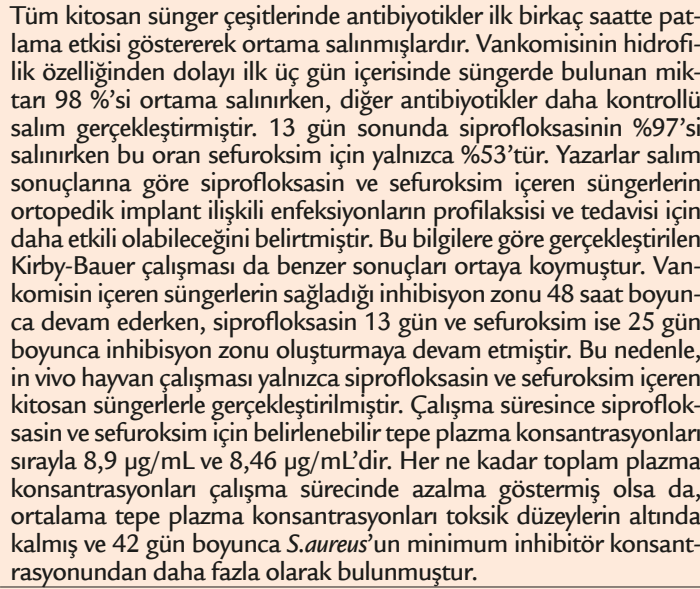 \\
\hline
\end{tabular}


Derlenen tüm çalışmalara göre kontrollü antibiyotik salım sistemleri ile erken dönemde biyofilm oluşumunun engellenmesi enfeksiyonun kontrolü için altın kurallardandır. Enfeksiyona neden olan patojenlerin çeşitliliği göz önüne alındığında kontrollü ilaç salım sistemlerinde patojen çeşidine göre antibiyotik seçimi ve seçilen antibiyotiğin hidrofilik özelliklerine göre sistemlerin uzun süre boyunca kontrollü salım gerçekleştirecek şekilde tasarlanması büyük önem taşımaktadır.

\section{KAYNAKLAR}

1. Drago L, Clerici P, Morelli I, Ashok J, Benzakour T, Bozhkova S, Alizadeh C, del Sel H, Sharma HK, Peel T, Mattina R, Romanò CL. The World Association against Infection in Orthopaedics and Trauma (WAIOT) procedures for Microbiological Sampling and Processing for Periprosthetic Joint Infections (PJIs) and other Implant-Related Infections. J Clin Med 2019;8(7):933. Crossref

2. Arciola CR, Campoccia D, Montanaro L. Implant infections: adhesion, biofilm formation and immune evasion. Nat Rev Microbiol 2018;16(7):397-409. Crossref

3. Tuon FF, Cieslinski J, Ono AFM, Goto FL, Machinski JM, Mantovani LK, Kosop LR, Namba MS, Rocha JL. Microbiological profile and susceptibility pattern of surgical site infections related to orthopaedic trauma. Int Orthop 2019;43(6):1309-13. Crossref

4. Oliveira WF, Silva PMS, Silva RCS, Silva GMM, Machado G, Coelho LCBB, Correia MTS. Staphylococcus aureus and Staphylococcus epidermidis infections on implants. J Hosp Infect 2018;98(2):111-7. Crossref

5. Jamal M, Ahmad W, Andleeb S, Jalil F, Imran M, Nawaz MA, Hussain T, Ali M, Rafiq M, Kamil MA. Bacterial biofilm and associated infections. J Chinese Med Assoc 2018;81(1):7-11. Crossref

6. Gross M, Cramton SE, Götz F, Peschel A. Key role of teichoic acid net charge in Staphylococcus aureus colonization of artificial surfaces. Infect Immun 2001;69(5):3423-6. Crossref

7. Lerch MF, Schoenfelder SM, Marincola G, Wencker FD, Eckart M, Förstner KU, Sharma CM, Thormann KM, Kucklick $\mathrm{M}$, Engelmann S, Ziebuhr W. A non-coding RNA from the intercellular adhesion (ica) locus of Staphylococcus epidermidis controls polysaccharide intercellular adhesion (PIA)-mediated biofilm formation. Mol Microbiol 2019;111(6):1571-91. Crossref

8. Ma L, Feng S, Fuente-Núñez CDL, Hancock RE, Lu X. Development of molecularly imprinted polymers to block quorum sensing and inhibit bacterial biofilm formation. ACS Appl Mater Interfaces 2018;10(22):18450-7. Crossref

9. Omar A, Wright JB, Schultz G, Burrell R, Nadworny P. Microbial biofilms and chronic wounds. Microorganisms 2017;5(1):9-23. Crossref

10. Peeters E, Nelis HJ, Coenye T. Comparison of multiple methods for quantification of microbial biofilms grown in microtiter plates. J Microbiol Methods 2008;72(2):157-65. Crossref
11. Hassan A, Usman J, Kaleem F, Omair M, Khalid A, Iqbal M. Evaluation of different detection methods of biofilm formation in the clinical isolates. Braz J Infect Dis 2011;15(4):305-11. Crossref

12. Yang F, Cui W, Xiong Z, Liu L, Bei J, Wang S. Poly (L, L-lactideco-glycolide)/tricalcium phosphate composite scaffold and its various changes during degradation in vitro. Polym Degrad Stab 2006;91(12):3065-73. Crossref

13. Bryers JD. Medical biofilms. Biotechnol Bioeng 2008;100(1):1-18. Crossref

14. Mauri E, Negri A, Rebellato E, Masi M, Perale G, Rossi F. Hydrogel-nanoparticles composite system for controlled drug delivery. Gels 2018;4(3):74-85. Crossref

15. Liechty WB, Kryscio DR, Slaughter B V., Peppas NA. Polymers for Drug Delivery Systems. Annu Rev Chem Biomol Eng 2010;1:149-73. Crossref

16. Langer R, Peppas NA. Advances in Biomaterials, Drug Delivery, and Bionanotechnology. AIChE J 2003;49(12):2990-3006. Crossref

17. Kankilic B, Bilgiç E, Korkusuz P, Korkusuz F. Vancomycin containing PLLA/ $\beta$-TCP controls experimental osteomyelitis in vivo. J Orthop Surg Res 2014;9:114. Crossref

18. Aragón J, Feoli S, Irusta S, Mendoza G. Composite scaffold obtained by electro-hydrodynamic technique for infection prevention and treatment in bone repair. Int J Pharm 2019;557:162-9. Crossref

19. Balato G, Roscetto E, Vollaro A, Galasso O, Gasparini G, Ascione T, Catania MR, Mariconda M. Bacterial biofilm formation is variably inhibited by different formulations of antibiotic-loaded bone cement in vitro. Knee Surg Sports Traumatol Arthrosc 2019;27(6):1943-52. Crossref

20. Barros JAR, de Melo LDR, da Silva RAR, Ferraz MP, de Rodrigues Azeredo JCV, de Carvalho Pinheiro VM, Colaço BJA, Raposo Fernandes MH, de Sousa Gomes P, Monteiro FJ. Encapsulated bacteriophages in alginate-nanohydroxyapatite hydrogel as a novel delivery system to prevent orthopedic implant-associated infections. Nanomedicine 2020;24:102145. Crossref

21. Horprasertkij K, Dwivedi A, Riansuwan K, Kiratisin P, Nasongkla N. Spray coating of dual antibiotic-loaded nanospheres on orthopedic implant for prolonged release and enhanced antibacterial activity. J Drug Deliv Sci Technol 2019;53:101102. Crossref

22. Macha IJ, Karacan I, Ben-Nissan B, Cazalbou S, Müller $\mathrm{WH}$. Development of antimicrobial composite coatings for drug release in dental, orthopaedic and neural prostheses applications. SN Applied Sci 2019;1(1):68. Crossref

23. Qiao Z, Yuan Z, Zhang W, Wei D, Hu N. Preparation, in vitro release and antibacterial activity evaluation of rifampicin and moxifloxacin-loaded poly(D, L-lactide-coglycolide) microspheres. Artif Cells Nanomed Biotechnol 2019;47(1):790-8. Crossref

24. Pawar V, Bulbake U, Khan W, Srivastava R. Chitosan sponges as a sustained release carrier system for the prophylaxis of orthopedic implant-associated infections. Int J Biol Macromol 2019;134:100-12. Crossref 